\title{
ANALYSIS OF STAGE-STRUCTURED MODEL WITH MIXED TYPE OF FUNCTIONAL RESPONSE AND IMPULSIVE BIOLOGICAL CONTROL
}

\author{
Bhanu Gupta, Amit Sharma, Joydip Dhar and SAnjay K. SRIVAStava
}

\begin{abstract}
The aim of this paper is to study a stage-structured pest management model with mixed type of functional response i.e., Holling type-I and Beddington-DeAngelis functional response with impulsive biological control. Stage structuring is proposed due to the fact that almost all the pests in their life pass through two stages namely, immature larva and mature adult. It is assumed that immature susceptible pests and exposed pests are attacked by a natural enemy and susceptible pests (immature and mature) are contacted by infected pests which make them exposed. Infected pests and natural enemies are infused impulsively after fixed intervals. All positive solutions are proved to be uniformly ultimately bounded. The stability analysis of pest extinction periodic solution, as well as the permanence of system, are obtained by making use of floquet's theory, small amplitude perturbation technique, and comparison theorem. The results obtained provide certain dependable theoretical findings for effective pest management. At last, theoretical findings are confirmed by means of numerical simulation.
\end{abstract}

Mathematics subject classification (2010): 92D25, 34C11.

Keywords and phrases: Beddington-DeAngelis functional response, pest management, impulsive effect, stability analysis, permanence.

\section{REFERENCES}

[1] W. Aktar, D. Sengupta And A. Chowdhury, Impact of pesticides use in agriculture: their benefits and hazards, Interdisciplinary toxicology, 2, 1 (2009), 1-12.

[2] H. BEAK, A food chain system with Holling type IV functional response and impulsive perturbations, Computers \& Mathematics with Applications, 60, 5 (2010), 1152-1163.

[3] J.R. Beddington, Mutual interference between parasites or predators and its effect on searching efficiency, The Journal of Animal Ecology, (1975), 331-340.

[4] R.S. CANTRELl AND C. Cosner, On the dynamics of predator-prey models with the BeddingtonDeAngelis functional response, Journal of Mathematical Analysis and Applications, 257, 1 (2001), 206-222.

[5] D.L. DeAngelis, R. A. Goldstein And R.V. O'neill, A model for tropic interaction, Ecology, 56, 4 (1975), 881-892.

[6] K.S. JATAV AND J. DHAR, Hybrid approach for pest control with impulsive releasing of natural enemies and chemical pesticides: A plant-pest-natural enemy model, Nonlinear Analysis: Hybrid Systems, 12 (2014), 79-92.

[7] V. Kumar, J. Dhar AND H.S. Bhatti, Stability and Hopf bifurcation dynamics of a food chain system: plant-pest-natural enemy with dual gestation delay as a biological control strategy, Modeling Earth Systems and Environment, 4, 2 (2018), 881-889.

[8] V. Kumar, J. Dhar And H.S. BhatTi, Stage-structured plant-pest-natural enemy interaction dynamics incorporating gestation delay for both pest and natural enemy, Modeling Earth Systems and Environment, 4, 3 (2018), 1-11.

[9] V. Kumari, S. Chauhan, S.K. Bhatia, J. Dhar, Plant-Pest-Natural Enemy Model With Impulsive Biological and chemical control, Differential Equations and Applications, 10, 4 (2018), 413-31.

[10] J.M. KoTCHEN, Incorporating resistance in pesticide management: a dynamic regional approach, Regional Sustainability, (1999), 126-135. 
[11] K.S. MathUR AND J. Dhar, Stability and permanence of an eco-epidemiological SEIN model with impulsive biological control, Computational and Applied Mathematics, (2016), 1-16.

[12] V. LaKshmikAntham, D.D. Bainov AND P.S. SimeOnov, Theory of impulsive differential equations, World Scientific, 1989.

[13] K. Negi AND S. GAKKHAR, Dynamics in a Beddington-DeAngelis prey-predator system with impulsive harvesting, Ecological Modelling, 206, 3 (2007), 421-430.

[14] R. SHI AND L. ChEn, Stage-structured impulsive SI model for pest management, Discrete Dynamics in Nature and Society,(2007).

[15] X. WANG AND X. Song, Analysis of an impulsive pest management SEI model with nonlinear incidence rate, Computational \& Applied Mathematics, 29, 1 (2010), 1-17.

[16] S. WANG AND Q. HUANG, Bifurcation of nontrivial periodic solutions for a Beddington-DeAngelis interference model with impulsive biological control, Applied Mathematical Modelling, 39, 5 (2015), $1470-1479$.

[17] Z. Xiang, L. Yongfeng And X. Song, Dynamic analysis of a pest management SEI model with saturation incidence concerning impulsive control strategy, Nonlinear Analysis: Real World Applications, 10, 4 (2009), 2335-2345.

[18] H. Yu, S. Zhong AND R. P. Agarwal, Mathematics analysis and chaos in an ecological model with an impulsive control strategy, Communications in Nonlinear Science and Numerical Simulation, 16, 2 (2011), 776-786.

[19] H. Zhang, P. Georgescu And L. Chen, An impulsive predator-prey system with BeddingtonDeangelis functional response and time delay, International Journal of Biomathematics, 1, 1 (2008), $1-17$.

[20] H. Zhang, P. Georgescu And L. Chen, On the impulsive controllability and bifurcation of a predator-pest model of IPM, BioSystems, 93, 3 (2008), 151-171.

[21] H. ZhANG, J. JIAO AND L. CHEN, Pest management through continuous and impulsive control strategies, BioSystems, 90, 2 (2007), 350-361.

[22] S. Zhang AND L. Chen, A study of predator-prey models with the Beddington-DeAnglis functional response and impulsive effect, Chaos, Solitons \& Fractals, 27, 1 (2006), 237-248.

[23] X. Zhou, X. Song AND X. SHI, Analysis of competitive chemostat models with the BeddingtonDeAngelis functional response and impulsive effect, Applied Mathematical Modelling, 31, 10 (2007), 2299-2312.

[24] B. Gupta, A. Sharma And S.K. SRIVAstava, Mathematical Study of Hybrid Impulsive Pest Control Model with Stage Structuring, Journal of the Indian Mathematical Society, 85, 3-4 (2018), 265290. 